\title{
ANÁLISE DA PAISAGEM DA BACIA HIDROGRÁFICA RIO RIOZINHO - JANIÓPOLIS/PR
}

\author{
Jonathan Santos Pericinoto $^{(\mathrm{a})}$, Ana Paula Colavite ${ }^{(\mathrm{b})}$

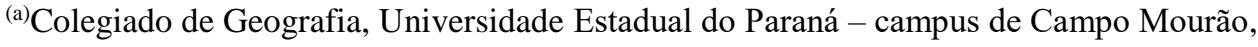 \\ jpgeoprocessamento@gmail.com \\ (b) Colegiado de Geografia, Universidade Estadual do Paraná - campus de Campo Mourão, apcolavite @ hotmail.com
}

\section{Eixo: GEOTECNOLOGIAS E MODELAGEM ESPACIAL EM GEOGRAFIA FÍSICA}

\begin{abstract}
Resumo
A pesquisa teve como objetivo a construção de um conjunto de mapas temáticos e outros produtos cartográficos representando a dinâmica da paisagem da bacia hidrográfica do rio Riozinho. A bacia hidrográfica tem sido modificada constantemente devido às ações antrópicas em seu espaço, assim a análise desse espaço torna-se necessária para compreender a dinâmica envolvida entre o homem e o meio natural.O desenvolvimento da pesquisa foi realizado atráves de geotecnologias que auxiliram na construção do banco de dados e análise do material.A ánalise da bacia, a partir de mapas com foco na análise da paisagem, proporcionoucompreender as relações do meio natural com o espaço modificado pela sociedade, seguindo na compreensão dos agentes nesse espaço como a própria bacia.A pesquisa apresenta como resultado, um banco de dados com análise de parâmetros morfométricos e topológicos da bacia hidrográfica.
\end{abstract}

Palavras chave: Dinâmica; Sociedade; Natureza; SIG; Cartografia.

\section{Introdução}

A bacia hidrográfica apresenta-se como um importante recorte espacial para o desenvolvimendo de pesquisas científicas, pois a partir deste sistema é possivel compreender as relações estabelecidas entre a sociedade e a natureza. Ademais a esta delimitação estão associados o planejamento de construções para beneficio e desenvolvimento da sociedade humana, para os quais o abastecimento hídrico domiciliar, industrial e de outros usos é fundamental.

A área da bacia hidrográfica pode ser entendida como um espaço natural, no qual escoam as águas das chuvas abastecendo o canal principal e seus afluentes. As caracteristicas predominantes consistem nos elementos que definem a bacia, seu limite superior é o divisor de água e a delimitação inferior é a saída para um canal de ordem superior, sendo importante também outros elementos comoo relevo, a cobertura vegetal, dentre outros (LIMA, 2008). O conhecimento da área de manejo, torna-se essencial para que o uso de recursos naturais não seja prejudicado e que se mantenha o equilibrio do ecossistema. 


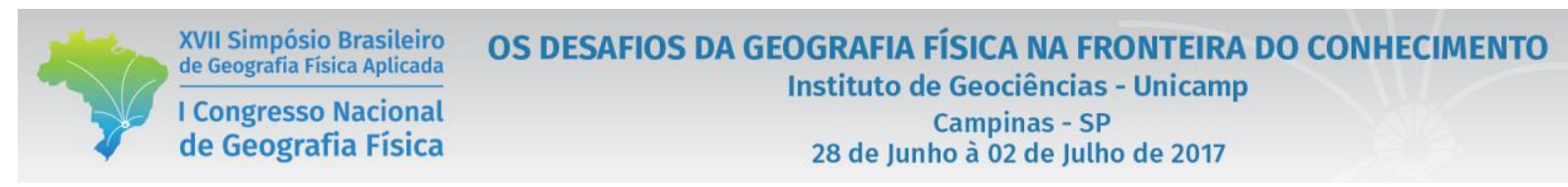

Os estudos morfométricos são responsáveis pelo fornecimento de dados métricos que auxiliam na compreensão das formas presentes na bacia hidrográfica (COLAVITE, 2010). Ademais auxiliam na análise da bacia, pois segundo Christofoletti (1981) "a análise da rede hidrográfica pode levar à compreensão de numerosas questões geomorfológicas, pois os cursos de água constituem processo morfogenético dos mais ativos na esculturação da paisagem terrestre". Os dados adquiridos possuem uma maior representatividade quando utilizadosna forma de representação espacial e, neste caso, as geotecnologias favorecem o planejamento ambiental.A pesquisa teve como objetivo realizar o mapeamento da bacia hidrográfica rio Riozinho (Paraná) e a análise correlacionada com os parametros morfométricos e topológicos.

\section{Metodologia e Procedimentos}

A pesquisa adotou como recorte espacial a bacia hidrográfica do rio Riozinho(figura 1), situada nos municipios de Janiópolis, Farol, Boa Esperança e Mamborê (na mesorregião Centro Ocidental Paranaense), sendo uma subbacia do rio Goioerê, que por sua vez faz parte da bacia do rio Piquiri e este desagua no rio Paraná.

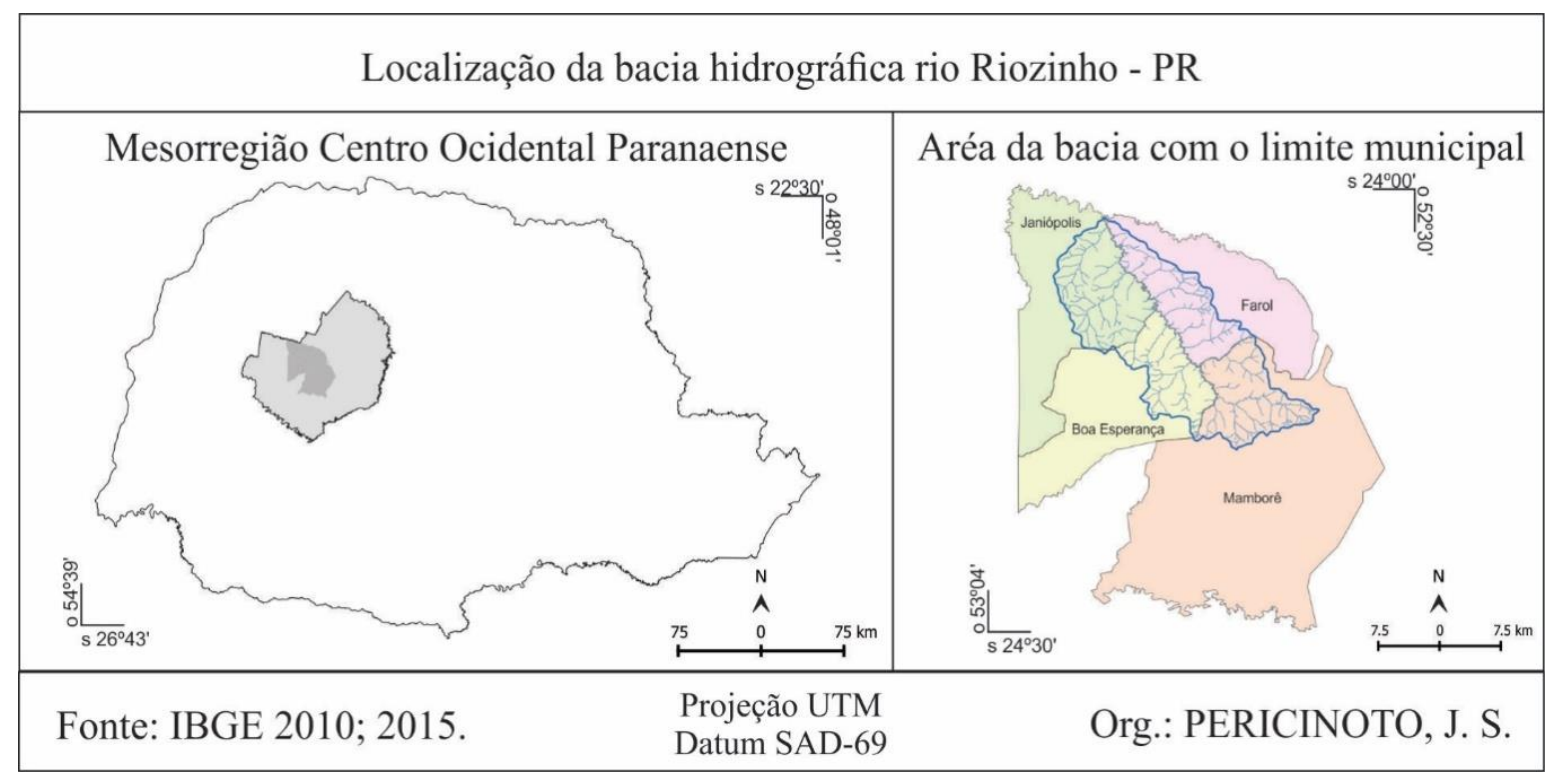

Figura 1 - Localização da bacia hidrográfica rio Riozinho

A elaboração dos mapas e análises espaciais utilizou o SIG Spring (versão 5.1.8) e a edição final dos mapas foi realizada no Corel Draw. A base cartográfica foi composta pelas cartas topográficas: SG.22-VA-III-1MI-2802/1 (Janiópolis); SG.22-V-A-III-2 MI-2802/2 (Farol); SG.22-V-A-III-2 MI-2802/4 (Mamborê), as quais foram obtidas no site do Instituto de Terras, Cartografia e Geociências (ITCG) na 
escala de 1:50.000. Por edição vetorial foram extraídos os limites da bacia e a rede hidrográfica, a qual foi hierarquizada de acordo com Strahler (1964).Os dados SRTM/Topodata, serviram de base para construção dos mapas de hipsometria, declividade e orientação das vertentes.

Os cálculos morfométricos foram realizados de acordo com Christofoletti (1969), Christofoletti et al. (1981), Tucci (1997), Silva et al (2003), utilizando os parâmetros: área e perimetro da bacia; ordenamento dos canais; número de canais; densidade hidrográfica e de drenagem; extensão do percurso superficial; relação de bifurcação; coeficiente de manutenção; amplitude altimétrica; rugosidade topográficae; índice de forma "K".

\section{Resultados e Discussão}

Com base nos cálculos de análise morfométrica identifica-se que a bacia hidrográfica do rio Riozinho representa uma área superficial mediana, com relevância no nível local, apresentando aproximadamente $453 \mathrm{Km}^{2}$ e um perímetro de $116 \mathrm{Km}$, distribuidos em um formato alongado, corroborando com o Indice de Forma que resultou em 1,51.

Apresenta ordem final 5 (figura $2 \mathrm{~A}$ ), com o canal principal orientado de sudeste à noroeste.A bacia hidrográfica é formada por:226 canais de ordem 1 (somando $223 \mathrm{Km}$ de comprimento) e com relação de bifurcação da ordem de 4,43; 51 canais de ordem 2 (somando $121 \mathrm{~km}$ ) e relação de bifurcação de 4,25; 12 canais de ordem 3 (somando $61 \mathrm{~km}$ ) e relação de bifurcação de 4; 3 canais de ordem 4 (somando $13 \mathrm{~km}$ ) e relação de bifurcação de 1,5; e o canal principal de ordem 5 com $51 \mathrm{~km}$ de extensão.

A densidade hidrográfica corresponde à presença de 0,498 canais $/ \mathrm{km}^{2}$ e a densidade de drenagem indicou $1,038 \mathrm{~km} / \mathrm{km}^{2}$. A extensão percorrida por águas de enxurradas até encontrar um canal, ou extensão do percurso superficial, corresponde à aproximadamente $481 \mathrm{~m}$ e o coeficiente de manutenção da bacia consiste em $963 \mathrm{~m}^{2}$.

Com relação à altitude, situa-se entre as cotas de 407 e 763 metros, com amplitude altimétrica de 356 metros e rugosidade topográfica da ordem de $369 \mathrm{~km} / \mathrm{Km}^{2}$. Esse gradiente altimétrico foi representado no mapa de hipsometria (figura 2B) subdividido em 8 faixas de 50 metros de altitude cada uma. Cabe destacar que a largura das faixas hipsométricas é muito semelhante por toda bacia, indicando que o relevo segue um padrão de modelado muito semelhante em todo seu curso. 


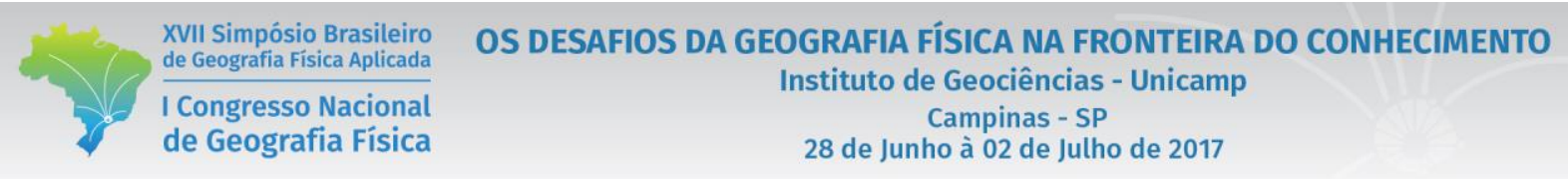

A declividade da bacia hidrográfica do rio Riozinho (figura $2 \mathrm{C}$ ) situa-se especialmente entre 0 a $20 \%$, subdivididos da seguinte forma: a faixa de 0 a 3\% predomina nas áreas mais altas, que são os divisores de drenagem dos cursos hidricos secundários; a faixa de 3 a $8 \%$ concentra-se nas altas e médias vertentes; a faixa de 8 a 20\% localiza-se na proximidade dos canais de drenagem, na baixa vertente; e as demais faixas foram encontradas em pequenos fragmentos dispersos pela área da bacia.

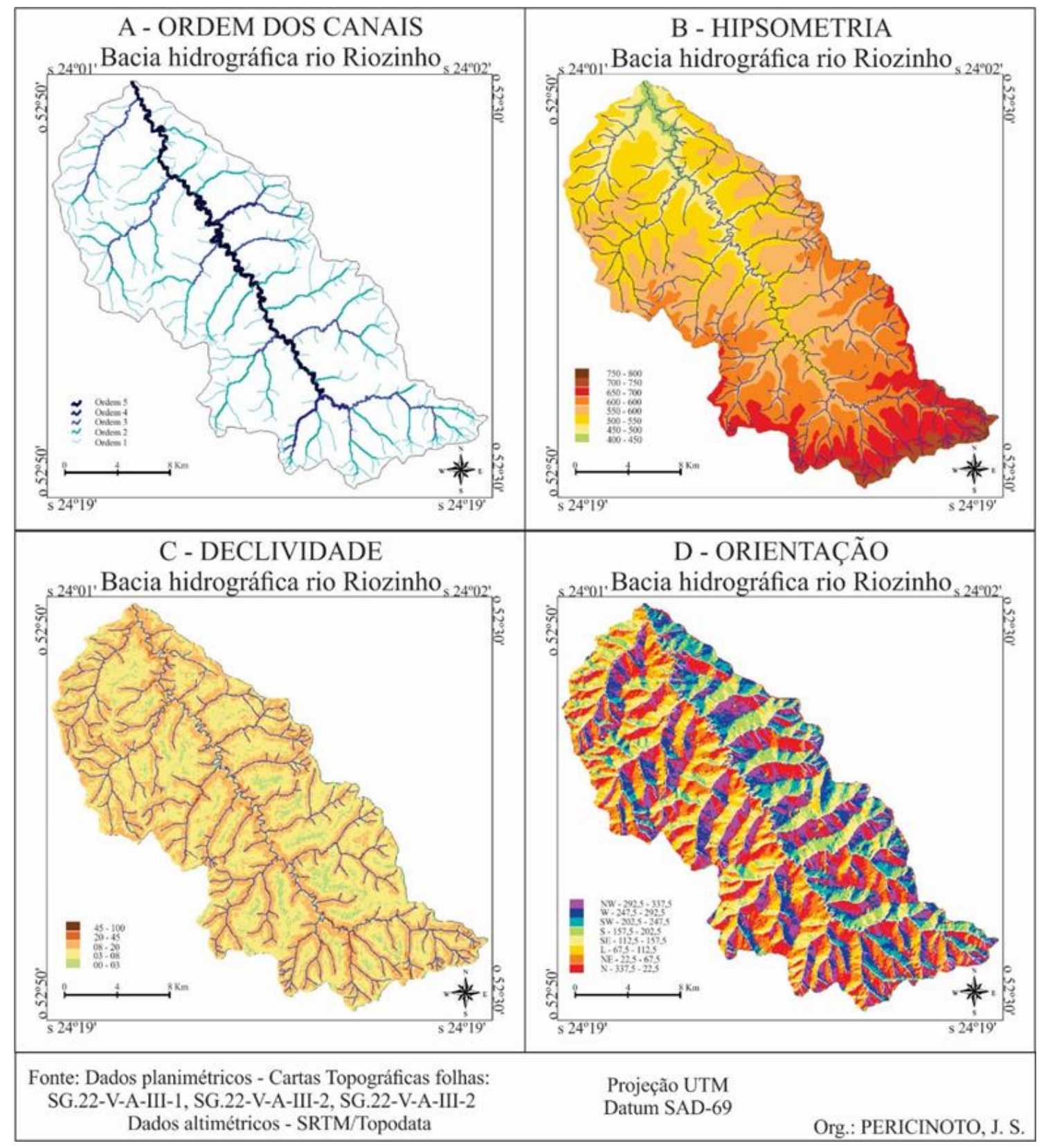

Figura 2A - Ordem dos canais; Figura 2B - Hipsometria; Figura 2C - Declividade; Figura 2D - Orientação 
Com relação à direção da face das vertentes da bacia hidrográfica, conforme pode ser observado no mapa de orientação (figura 2D), há um considerável equilibrio entre as direções, sendo que de acordo com os valores de área obtidos para cada orientação tem-se: as faces norte e noroeste são as de maior predominio com $17 \%$ do território cada classe; as faces nordeste e oeste na sequencia apresentam $13 \%$ de ocupação territorial cada classe; as demais faces - sul, leste, sudeste e sudoeste - ocupam $10 \%$ de área total, cada classe.

\section{Considerações Finais}

Considerando a produção cartográfica realizada no desenvolvimento da pesquisa e as análises tecidas, observou-se que a dinamica da paisagem da bacia hidrográfica do rio Riozinho apresenta-se semelhante em todo trajeto, apresentado área e projeção regional medianas.

Com relação à fragilidade ambiental, considerando os aspectos analisados, na bacia são encontrados baixos índices de fragilidade e neste sentido alta aptidão para o uso intensivo da terra, corroborando com os aspectos que são observados in loco, especialmente relacionados à alta mecanização agrícola e pequenas parcelas de área preservadas.

\section{Agradecimentos}

Agradecimento a Fundação Araucária pela bolsa a Iniciação Cientifica através do programa PIBIC.

\section{Bibliografia}

CHRISTOFOLETTI, A. Análise morfométrica das bacias hidrográficas.Notícia Geomorfológica, Campinas, 9(18): 35-69, 1969.

CHRISTOFOLETTI, A.Geomorfologia. São Paulo: Edgard Blücher. 1981.

Christofoletti, A; GUERRA, C. E. C; MAgnavitA, I. M. P; MARTins, M. R. \&TAVARES, A. C. Contribuição à análise morfométrica das regiões das bacias do Jequitinhonha e Extremo Sul, no Estado da Bahia. Notícia Geomorfológica. Campinas, 21(41): 61-84, 1981.

COLAVITE, A. P. Geotecnologias aplicadas à análise morfométrica da bacia hidrográfica do rio do Campo, Campo Mourão -PR. In: SIMPÓSIO BRASILEIRO DE CARTOGRAFIA GEOTÉCNICA E GEOAMBIENTAL, 7, 2010, Maringá. Anais... Maringá: Universidade Estadual de Maringá, 2010. p. 1-10. 


$\begin{aligned} & \text { XVII Simpósio Brasileiro } \\ & \text { de Geografia Fisica Aplicada }\end{aligned}$
$\begin{aligned} & \text { I Congresso Nacional } \\ & \text { de Geografia Física }\end{aligned}$

LIMA, W. P. Hidrologia Florestal Aplicada ao Manejo de Bacias Hidrográficas. Escola Superior de Agricultura "Luiz de Queiroz", Departamento de Ciências Florestais, Piracicaba - São Paulo. Universidade deSão Paulo, 2008.

TUCCI, C. E. M. Hidrologia - ciência e aplicação. Editora da Universidade (UFRGS)/Edusp/ABRH, Porto Alegre, RS, 1997. 